\title{
Percutaneous transforaminal endoscopic discectomy for the treatment of lateral recess stenosis secondary occurred the discal fungus infection
}

Yunpeng Fan ${ }^{1 \dagger}$, Tao Xie $^{2 \dagger}$, Yao Pang ${ }^{1}$, Liulong Zhu ${ }^{1,2}$ and Shaobo Zhou ${ }^{2 *}$

\begin{abstract}
Background: This is a case of lateral recess stenosis secondary occurred the discal fungus infection treated with percutaneous transforaminal endoscopic discectomy (PTED). There has been no relevant reports before.

Case presentation: A 49-year-old patient who had taken itraconazole for 13 months for lateral recess stenosis secondary occurred the discal fungus infection complained of gradually worsening radiating pain and numbness in the back and inguinal and inner thigh region of right side. In order to relieve the radiating neuralgia and reduce the damage to spinal stability, the minimally invasive PTED was performed.The patient's prognosis was assessed using Oswestry Disability Index (ODI) and Visual Analogue Scale (VAS).

During the follow-up, the patient's ODI and VAS scores were decreased significantly. The radiating pain in the inguinal and inner thigh region of right side were significantly alleviated and the discomfort caused by lower back instability was improved by plaster vest.
\end{abstract}

Discussion and conclusion: PTED not only avoids further damage to the stability of the lumbar spine, but also effectively relieves the symptoms of leg neuroradialgia caused by lateral recess stenosis secondary occurred the discal fungus infection.

Keywords: Lumbar spine, Lateral recess stenosis, Intervertebral infection, Fungus, Percutaneous transforaminal endoscopic discectomy

\section{Background}

Lateral recess stenosis is the common disease in elder people [1]. However, intervertebral disc fungal infection is very rare because only people with immune deficiency will develop this infection $[2,3]$.

\footnotetext{
* Correspondence: qq975137299@icloud.com

${ }^{\dagger}$ Yunpeng Fan and Tao Xie are joint first author and contributed equally to this study.

${ }^{2}$ The affiliated Hangzhou First People's Hospital, Zhejiang University School of Medicine Hangzhou, 261\# huansha road, Shangcheng District, Hangzhou City 310006, Zhejiang Province, China

Full list of author information is available at the end of the article
}

Early diagnosis and treatment of this infection is difficult because the symptoms are atypical and sometimes covered up by other diseases $[4,5]$. Nowadays, open surgery is widely accepted for the treatment of this [6] because it can expose the segmental visual field of the focus. However, the tissues undergo open surgery are more prone to damage and the subsequent infection, whereas minimally invasive surgery can decrease damage and better avoid post-operative infection [7, 8]. Here we report a case of lateral recess stenosis secondary occurred the discal fungus

(C) The Author(s). 2020 Open Access This article is licensed under a Creative Commons Attribution 4.0 International License, which permits use, sharing, adaptation, distribution and reproduction in any medium or format, as long as you give appropriate credit to the original author(s) and the source, provide a link to the Creative Commons licence, and indicate if changes were made. The images or other third party material in this article are included in the article's Creative Commons licence, unless indicated otherwise in a credit line to the material. If material is not included in the article's Creative Commons licence and your intended use is not permitted by statutory regulation or exceeds the permitted use, you will need to obtain permission directly from the copyright holder. To view a copy of this licence, visit http://creativecommons.org/licenses/by/4.0/ The Creative Commons Public Domain Dedication waiver (http://creativecommons.org/publicdomain/zero/1.0/) applies to the data made available in this article, unless otherwise stated in a credit line to the data. 


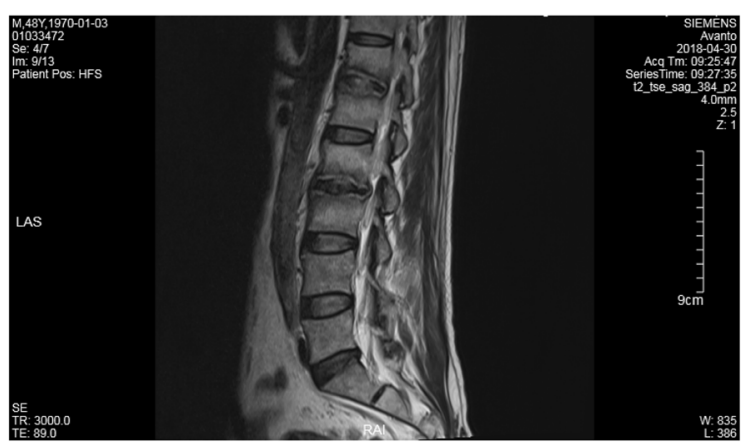

A
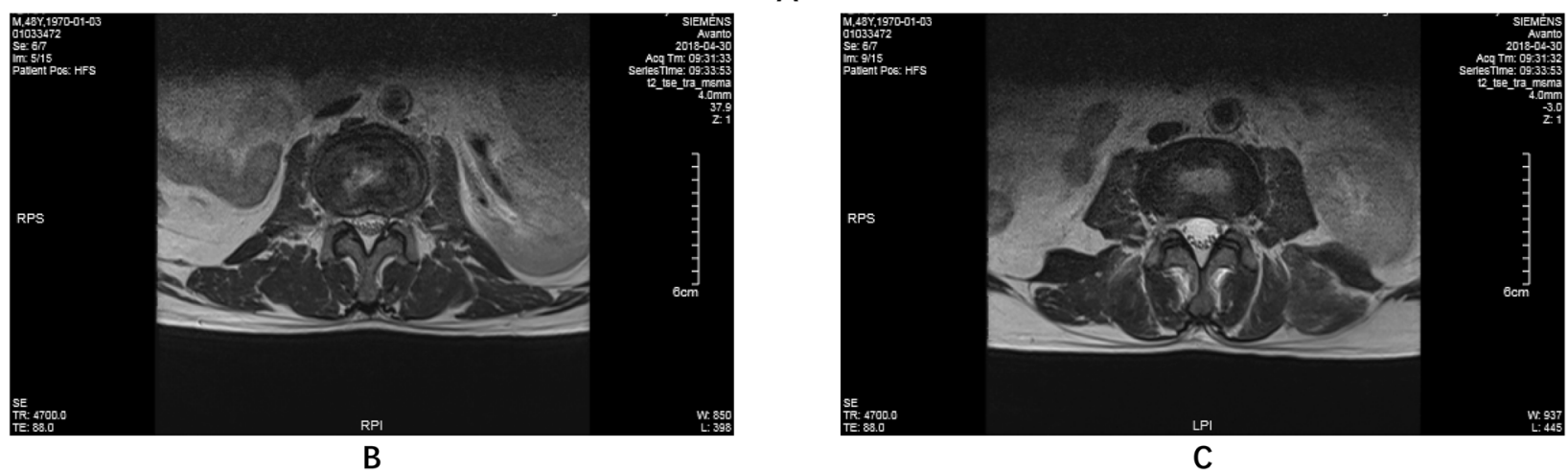

Fig. 1 Lumbar MRI (2018-04-30) a sagittal plane. b transverse section of T12/L1 c transverse section of L2/L3

infection treated with minimally invasive PTED in our hospital and evaluate the efficacy and feasibility of this technique.

\section{Case presentation}

A 49-year-old man complained of lumbar back pain and weakness accompanied by radiating pain in inguinal and inner thigh region of right side for one and a half years. Lumbar Magnetic Resonance Imaging (MRI) taken in April 302,018 showed abnormal high signal intensity in the T12/L1 and L2/3 lumbar intervertebral discs with lateral recess stenosis (Fig. 1); His C-reactive protein (CRP) was higher and white blood cell (WBC) count was lower than normal all the time (Fig. 2). Blood fungus culture confirmed Aspergillusflavus infections. The patient was given itraconazole $15 \mathrm{ml} /$ bid for 13 months before surgery. The lumbar back pain symptoms were relieved in a short term and no further damage was found in the vertebral body by MRI taken in Dec 11st, 2018 (Fig. 3). However, inguinal and inner thigh region radicular pain were not significantly improved in the one-year follow-up, so the patient came to our hospital in May 2019. One week later,we clean up the diseased tissue and made lateral recess plasty to expand the area of intervertebral foramen and relieve the radicular pain with PTED (Fig. 4). During the operation, some diseased tissues were taken for fungal culture. Meanwhile, antifungal agents (itraconazole) were injected into the intervertebral space. The pain in back and inguinal and inner thigh region of right side were ameliorated significantly after the operation. The patient was followed up for 9 months. His symptoms were improved significantly as shown by his ODI and VAS scores in Figs. 5 and 6.

\section{Discussion}

The endplates have more blood supply than the inner annulus fibrosus and nucleus pulposus. Therefore,

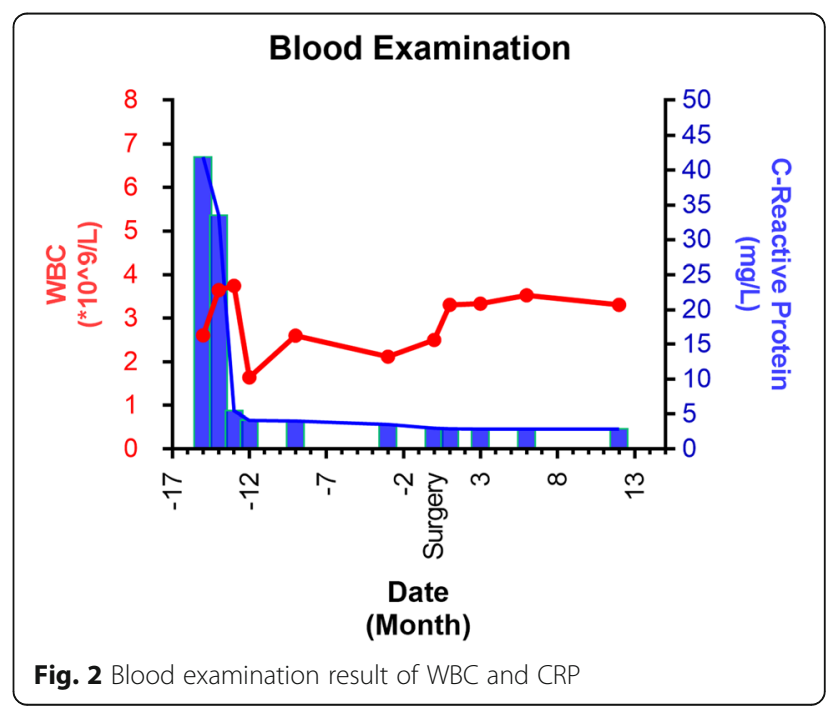




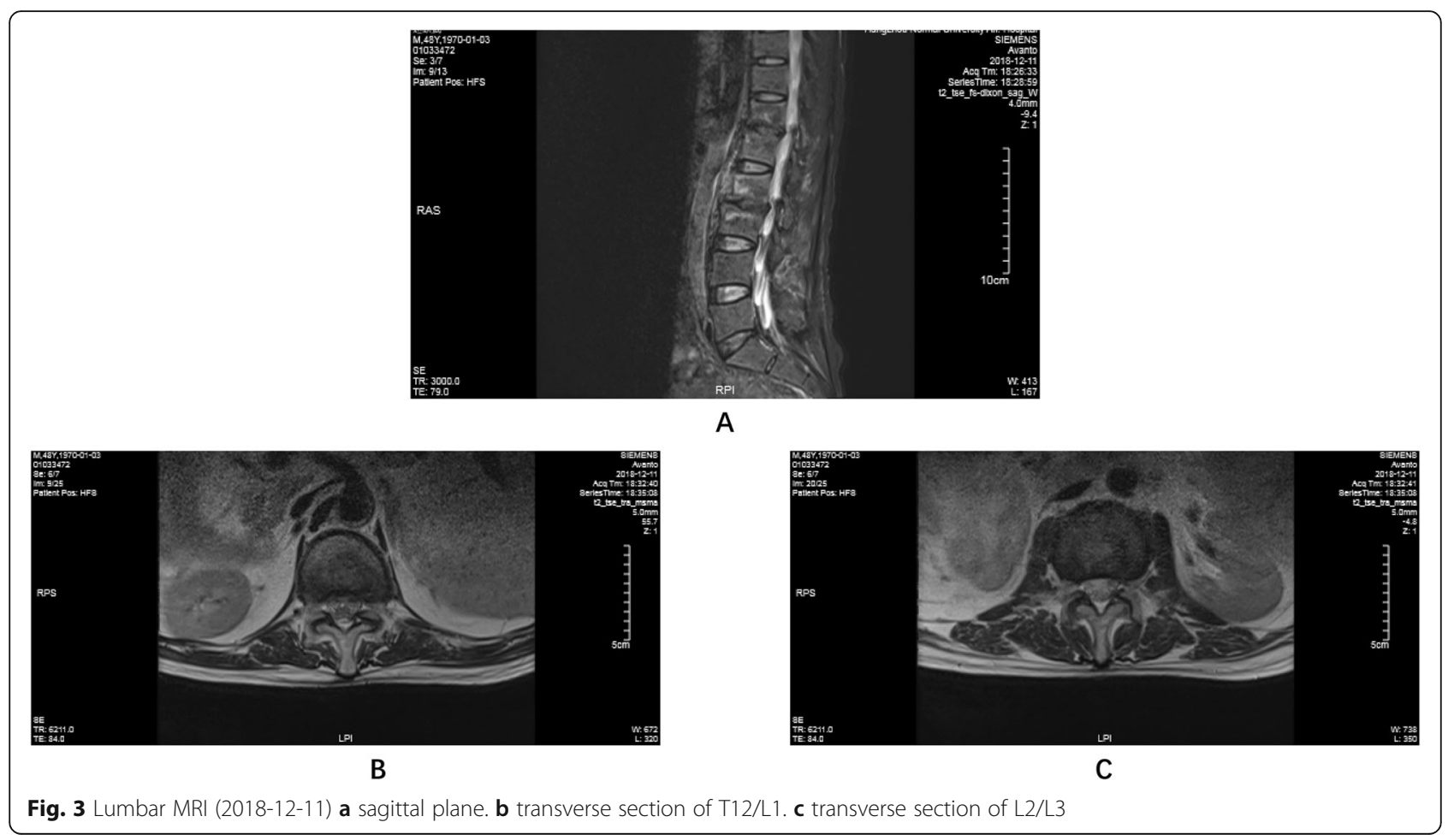

there might be two routes for lumbar intervertebral disc infection: 1. blood transmission; 2. direct contamination during operation [9]. Aspergillusflavus fungi were verified in this patient by blood culture. Most patients with fungal infections in intervertebral space have immunodeficiency diseases or long-term use of immunosuppressive drugs [10, 11]. However, none of the above-mentioned causes have been found in this patient. It is worth noticing that the patient has a history of liver cancer and his White Blood Cell (WBC) count was lower than normal. FeiMa and John W. Wilson mentioned that solid cancer could induce intervertebral fungal infection $[8,12]$. It is speculated that the long history of liver cancer suppressed the patient's immune function, thus leading to fungal infection of the spine.

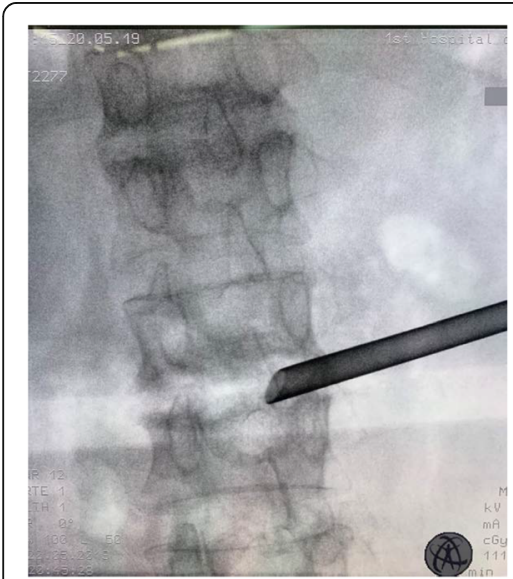

A

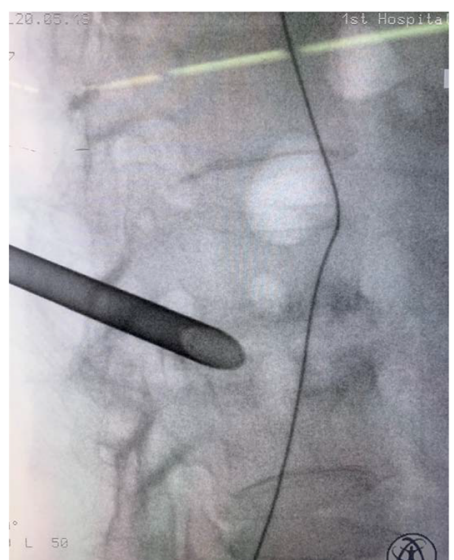

B

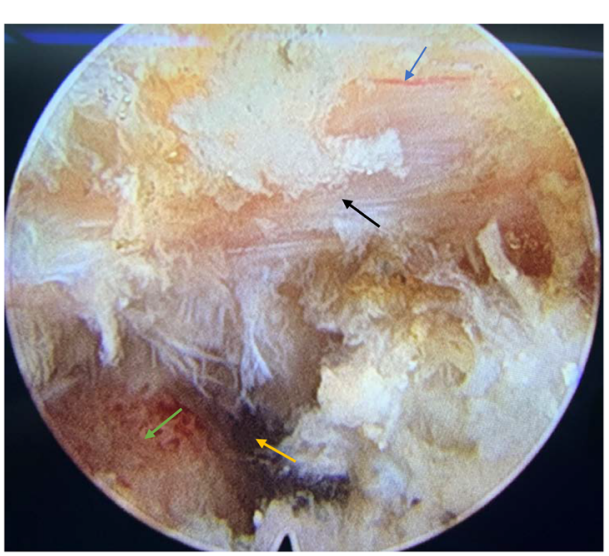

C

Fig. 4 Surgical process a lumbar anteroposterior X-ray film. b lumbar lateral X-ray film. c view of PTED (blue arrow: nerve root; black arrow: ligamentum flavum; green arrow:end plate; yellow arrow: intervertebral space) 


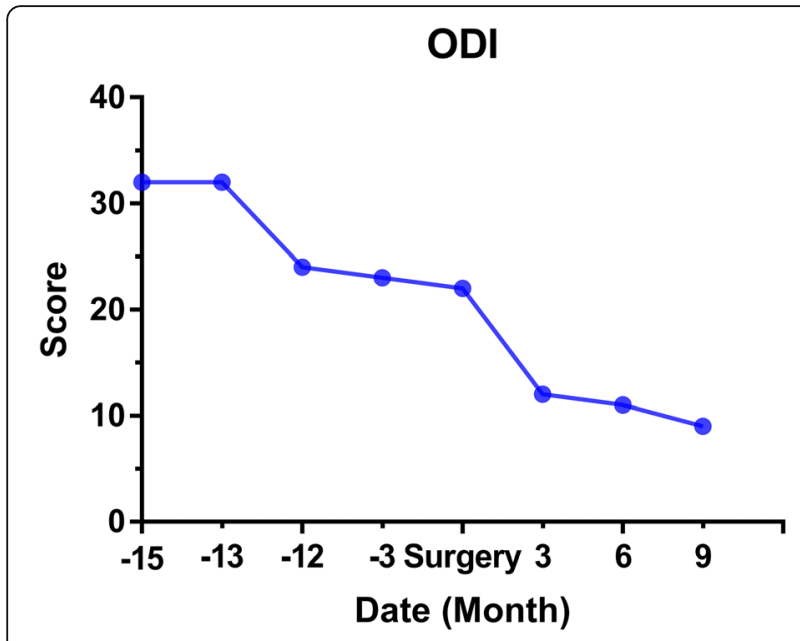

Fig. 5 ODI evaluation

Patients with fungal infection of the spine commonly have no obvious discomfort in the back at the early stage. The erosion of adjacent vertebral bodies or endplates gradually results in a decline in spinal stability. And some patients even suffer from radiating pain in the lower limb [13]. When the clinical symptoms occur, the condition has been developing for a long time, which then leads to a delayed diagnosis [14].

Because the patient had no significant improvement after taking itraconazole for 13 months as the conservative therapy, he expected surgical treatment. Considering the longterm fungal infection in his intervertebral space and the instability of his lumbar, our original plan was to fuse the diseased intervertebral space with cage and titanium bar for fixation. However, because of liver cancer, the patient's condition was poor, and he could not afford the cost of fusion and fixation. So the surgical method was abandoned. After further discussion, we believed that lateral recess stenosis caused the radiating pain in the inguinal and inner thigh region of right leg. Finally, we decided that the preferred treatment was PTED for lateral recess plasty to expand the intervertebral foramen and relieve the pain.

Due to the history of liver cancer and poor general condition, this patient can not tolerate multiple operations. After careful preoperative study of MRI images, we found that both T12-L1 and L2-L3 had intervertebral height loss and intervertebral foramen stenosis with lateral recess stenosis and thought the pain symptoms were caused for both segments. During the operation, we first performed PTED surgery on L2-L3 and radiating pain in inguinal and inner thigh region of right side still existed after root block of L2-L3. Combined with MRI, we continued to perform T12-L1 segment. According to $\mathrm{Hu}$ Chaohui and He Zhong et al., using local antibiotics was effective in treating intervertebral space infection [15, 16]. Therefore, local antifungal drugs were injected into the lesion site. Postoperative follow-up for 9 months revealed that the patient's inguinal and inner thigh region radiolurgic pain symptoms disappeared during activity.

Due to the long course of disease, the stability of intervertebral space was poor [17]. The patient was treated with gypsum vest fixation of the spine. After 9 months follow-up, the lumbar and inguinal and inner thigh region of right side pain was relived. This study confirmed that PTED is a good choice for the patient on antifungal agents for long-term fungal infection of the spine.

\section{VAS}

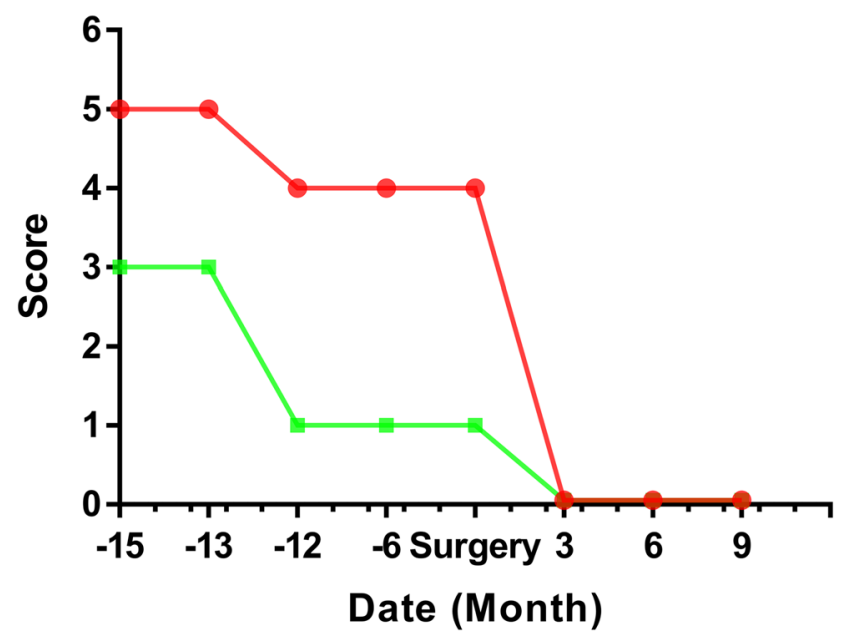

Fig. 6 VAS evaluation 


\section{Abbreviations}

CRP: C-Creative protein; MRI: Magnetic Resonance Imaging; ODI: Oswestry Disability Index; PTED: Percutaneous transforaminal endoscopic discectomy; VAS: Visual Analogue Scale; WBC: White blood cells

\section{Acknowledgements}

We thank Nanjing medical University library system for all of the help and resources and our deepest gratitude goes to the anonymous reviewers and editors for their careful work and thoughtful suggestions that have helped improve this paper substantially.

\section{Authors' contributions}

YPF conceived and designed the study and wrote this manuscript. SBZ searched database and reviewed studies. TX and YP performed data analysis and prepare the initial draft of the manuscript. LLZ participated in interpretation of data, helped in drafting the manuscript and critically reviewed the manuscript. All authors read and approved the final manuscript.

\section{Authors' information}

Not applicable

\section{Funding}

This research was supported by funder Liulong zhu with Medical Health Science and Technology Project of Hangzhou City (Grant No.: 20170533B38) and funder Tao Xie with Zhejiang province natural science Foundation of China (Grant No.: LQ17H160012.)

\section{Availability of data and materials}

The datasets used and/or analyzed during the current study are available from the corresponding author on reasonable request.

\section{Ethics approval and consent to participate}

Not applicable

\section{Consent for publication}

Written informed consent was obtained from the patient for publication of this case report and any accompanying images. A copy of the written consent is available for review by the Editor of this journal.

\section{Competing interests}

The authors declare that they have no competing interests.

\section{Author details}

${ }^{1}$ The Affiliated Hangzhou Hospital of Nanjing Medical University, Hangzhou 310006, China. ${ }^{2} T$ The affiliated Hangzhou First People's Hospital, Zhejiang University School of Medicine Hangzhou, 261\# huansha road, Shangcheng District, Hangzhou City 310006, Zhejiang Province, China.

Received: 15 September 2019 Accepted: 12 March 2020

Published online: 18 March 2020

\section{References}

1. Zhang LM, LV WY, Cheng G, et al. Percutaneous endoscopic decompression for calcified thoracic disc herniation using a novel T rigid bendable burr. $\mathrm{Br}$ J Neurosurg. 2019;33:1-3.

2. Maillard H, Ornetti P, Grimault L, Ramon JF, Ducamp SM, Saidani T, Tavernier C, Maillefert JF. Severe pyogenic infections in patients taking infliximab: a regional cohort study. Joint Bone Spine. 2005;72:330e4.

3. Wynne AT, Southgate GW. Discitis causing spondylolisthesis. A case report. Spine. 1986;11:970e2.

4. Cheung WY, Luk KD. Pyogenic spondylitis. Int Orthop. 2012;36:397e404.

5. Marín M, Ruiz A, Iglesias C, et al. Identification of Nocardia species from clinical isolates using Maldi-T-of Mass spectrometry. Clin Microbiol Infect. 2018;24:1342. e5-8.

6. Awad I, Bay JW, Petersen JM. Nocardial osteomyelitis of the spine with epidural spinal cord compression-a case report. Neurosurgery. 1984;15: 254-6.

7. Atalay B, Azap O, Cekinmez M, et al. Nocardial epidural abscess of the thoracic spinal cord and review of the literature. J Infect Chemother. 2005; 11:169-71.
8. Wilson JW. Nocardiosis: updates and clinical overview. Mayo Clin Proc. 2012; 87:403-7.

9. Xin HK, He Q. Adjacent intervertebral space infection after lumbar fusion. Orthopade. 2018;47:170-4.

10. Choi HJ, Kim W, Youn S, et al. Management of delayed infection after Insertion of bioresorbable plates at the infraorbital rim. J Craniofac Surg. 2012;23:524-5.

11. D'Agostino C, Scorzolini L, Massetti AP, et al. A seven-year prospective study on spondylodiscitis: epidemiological and microbiological features. Infection. 2010;38:102-7.

12. Ma F, Kang M, Liao YH, et al. Nocardial spinal epidural abscess with lumbar disc herniation. Medicine. 2018;97:49-54.

13. Kontoyiannis DP, Jacobson $\mathrm{KL}$, Whimbey EE, et al. Central venous catheterassociated nocardia bacteremia: an unusual manifestation of nocardiosis. Clin Infect Dis. 2000;31(2):617-8.

14. Brown-Elliott BA, Conville P, Wallace RJ. Current status of nocardia taxonomy and recommended identification methods. Clin Microbiol Newsl. 2015;37:25-32.

15. $\mathrm{Hu} \mathrm{CH}, \mathrm{Li} \mathrm{KH}, \mathrm{Li}$ B. Intermittent irrigation and drainage for lumbar interstitial infection. Chin J Bone Joint Inj. 2016;21:550-2.

16. He Z. Intermittent irrigation and drainage for lumbar interstitial infection. Chin Med Modern Distance Educ China. 2010;8:71-2.

17. Antunes JL. Infections of the spine. Acta Neurochir. 1992;116(2-4):179-86.

\section{Publisher's Note}

Springer Nature remains neutral with regard to jurisdictional claims in published maps and institutional affiliations.
Ready to submit your research? Choose BMC and benefit from:

- fast, convenient online submission

- thorough peer review by experienced researchers in your field

- rapid publication on acceptance

- support for research data, including large and complex data types

- gold Open Access which fosters wider collaboration and increased citations

- maximum visibility for your research: over $100 \mathrm{M}$ website views per year

At BMC, research is always in progress.

Learn more biomedcentral.com/submissions 